\title{
Para una estética de la presencia: cuerpo y sentido en "Lights in the City", de Alfredo Jaar*
}

FOR AN AESTHETIC OF PRESENCE: BODY AND SENSE IN "LIGHTS IN THE CITY" OFALFREDO JAAR

POR UMA ESTÉTICA DA EXISTÊNCIA: CORPO E SENTIDO "LIGHTS IN THE CITY" DE ALFREDO JAAR

\section{Jorge Ferrada Sullivan**}

Cuadernos de Música, Artes Visuales y Artes Escénicas

/Volumen 13 - Número 1 / Enero - Junio de 2018

/ ISSN 1794-6670/ Bogotá, D.C., Colombia / pp. 193-205

Fecha de recepción: 7 de abril de 2016

Fecha de aceptación: 16 de mayo de 2017

Disponible en línea: 6 de diciembre de 2017

doi:10.11144/javeriana.mavae13-1.puep una intervención artística realizada por el artista chileno Alfredo Jaar.

** Profesor en Historia y Geografía por la Universidad Católica Raúl Silva Henríquez, magíster en Artes mención Teoría e Historia del Arte por la Universidad de Chile y doctor en Filosofía mención Estética e Historia por la misma universidad. Académico de la Universidad de Los Lagos 


\section{Resumen}

El propósito de este artículo gira en torno a la relación que se puede establecer entre la creación artística y el gesto estético del creador. En términos particulares, el artista chileno Alfredo Jaar propuso para Montreal la obra Lights in the City (1999) como la presentación de una impronta estético-política al vincular en un espacio arquitectónico emblemático la instalación de la luminosidad de la obra con un cuerpo marginal de la sociedad canadiense. Este gesto del artista se transforma en una práctica de enunciación como recurso de mediación entre los signos de la instalación y el espectador. Dicha obra, se ubica sobre la cúpula del Mercado Bonsecours (Marché Bonsecours). Este corresponde a un viejo edificio en la ciudad de Montreal que sufrió históricamente reiterados incendios y simultáneos deterioros por su desamparo arquitectónico. Lo interesante de esta instalación es que además se prolonga 100 m más allá del monumento como tal. En ese espacio a distancia, se encuentra una serie de hospederías para todos aquellos hombres de la marginalidad que el Estado canadiense mantiene "velados" en dicha ciudad. Montreal es una de las ciudades más privilegiadas del desarrollo capitalista norteamericano y una de las ciudades más prósperas y bellas del continente. Para Jaar, la elección del lugar no significa cualquier lugar, sino el espacio de ese ahí-lugar, donde la acción estética sería impensada como gesto político. Bajo una revisión bibliográfica —-hermenéutica y explicativa - se vincula una serie de supuestos filosóficos y estéticos que permiten tensionar las maneras clásicas de abordar una obra de estas magnitudes, valorando finalmente el rol del arte como manifestación y presentación sensible de la realidad.

Palabras clave: instalación; site-specific; estética del disenso; brillantez/tacto del sentir

\section{Abstract}

The purpose of this article, revolves around the relationship that can be established between artistic creation and the aesthetic gesture of the creator. In specific terms the Chilean artist Alfredo Jaar proposed for the city of Montreal, the work lights in the City (1999) as the presentation of an estetica-politica linking in an emblematic architectural space, the installation of the lighting of the work with a marginal body of Canadian society. This gesture of the artist becomes a practice of enunciation as a resource of mediation between the signs of the installation and the Viewer. Such work, is located on the dome of Bonsecours Market. This corresponds to an old building in the city of Montreal that historically suffered repeated simultaneous fires and damage for its architectural helplessness. The interesting thing about this facility is also 100 meters past the monument as such is prolonged. In that space distance are a number of hostelries for all those men of marginality that the Canadian state remains "veiled" in the city. Montreal is one of the most privile- ged cities of the American capitalist development and one of the most prosperous and beautiful cities of the continent. For Jaar, the choice of location does not mean anywhere but the space there-place, where aesthetics action would be unthinkable as a political gesture. Under a —hermeneutics and explanatory — bibliographic review, linked a series of philosophical and aesthetic that you enable stress classical ways to address a work of these figures, finally appreciating the role of art as a manifestation and sensitive presentation of reality.

Keywords: installation; site-specific; aesthetic dissent; brightness; touch feel

\section{Resumo}

O objetivo do presente artigo, gira em torno da relação que pode ser estabelecida entre a criação artística e o gesto estético do criador. Em específico, termos a artista chilena Alfredo Jaar proposto para a cidade de Montreal, o trabalho de luzes da cidade (1999) como a apresentação de uma estetica-politica, vinculando-se em um espaço arquitectónico emblemático, imprimir a instalação da iluminação do trabalho com um corpo marginal da sociedade canadense. Este gesto do artista tornase uma prática de enunciação como um recurso de mediação entre os sinais da instalação e o espectador. Tal trabalho, situa-se cúpula de Mercado Bonsecours. Isto corresponde a um edifício velho na cidade de Montreal, que historicamente sofreram incêndios simultâneos repetidas e danos para a sua impotência arquitectónico. A coisa interessante sobre esta facilidade também é 100 metros após o monumento, como tal, é prolongado. Em que a distância espacial é um número de hospedarias para todos aqueles homens de marginalidade que o estado canadense permanece "velada" na cidade. Montreal é uma das cidades mais privilegiados do desenvolvimento capitalista americano e uma das cidades mais prósperas e belas do continente. Para Jaar, a escolha do local não significa qualquer lugar, mas o espaço não-lugar, onde a ação estética seria impensável como um gesto político. Em uma revisão de literatura - hermenêutica e explicativas-, estão ligados uma série de pressupostos estéticos e filosóficos que permitem que o estresse as clássicas maneiras de abordar uma obra dessas magnitudes, finalmente, apreciando o papel da arte como uma manifestação e apresentação sensível da realidade.

Palavras-chaves: instalação; site-specific; discordância estética; brilho/ sensação de toque 
Siempre hay un elemento de luz: lo necesito. Es verdad que está enmarcada en un espacio muy oscuro. Siempre me pregunto cuánta luz quiero dejar ver [...] Es una cosa objetiva, un elemento de esperanza. En cada obra está. En algunas no es tan evidente, pero está. Gracias a esta luz puedo seguir haciéndolas.

Alfredo Jaar

\section{“LIGHTS IN THE CITY”: UNA POÉTICA PARA LOS CUERPOS}

Hace casi una década el artista Alfredo Jaar sorprendió las noches de Montreal con las luces de la obra Lights in the City. La obra en cuestión correspondió a una instalación realizada en 1999 sobre la cúpula del Mercado Bonsecours (Marché Bonsecours), viejo edificio de la ciudad que sufrió históricamente reiterados incendios y permanentes abandonos. La obra, además, se prolonga casi $100 \mathrm{~m}$ más allá del monumento arquitectónico. En este nuevo lugar, se encuentra una serie de hospederías para todos aquellos hombres de la marginalidad y que se mantienen en un verdadero anonimato. En aquellas, cercanas al monumento, los indigentes podían pulsar un botón que, junto a un breve texto escrito por el artista, iluminaba la cúpula cada vez que se accionaba. En otras palabras, se recordaba permanentemente la presencia y el presente de la pobreza cada vez que era utilizado el circuito eléctrico. Sin duda, nuevos sentidos se nos aparecen al visualizar la proyección de la obra y la operatoria de la instalación. Una suerte de nuevas sensaciones que se exponen más allá del texto o de los textos que la puedan describir, ya que Jaar expuso con esta obra luces desde la cúpula que proyectaron los cuerpos que habitaban las hospederías. Por esta razón, la posibilidad de considerar esta intervención artística como la presentación de una impronta estético-política en la exposición de la luminosidad de la instalación se transformó en un signo del disenso.

El análisis epistemológico-filosófico de la obra radica en torno a la deconstrucción y la forma en que este gesto creativo nos permite entrar en una nueva problemática, que evidencia nuevas posibilidades de pensar el sentido de la obra. Una suerte de especulación que transforma el soporte luminosidad de la creación —recordando la marginalidad en Montreal- como el sentido de un aparecer de cuerpos expuestos a nuevas sensibilidades en su representación (figura 1)1.

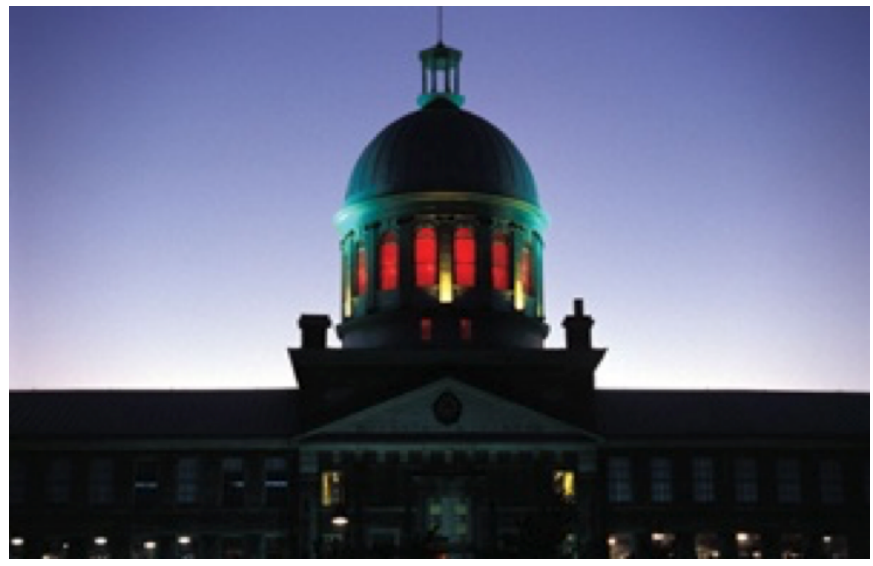

figura 1

Ligths in the City, 1999

Fuente: Alfredojaar.net (2013) 
La visibilidad de estos hombres sin lugar, sin parte, sin hogar, tendería a opacar la luminosidad y el esplendor de la ciudad ante el asalto sorpresivo de la suciedad, de lo mal oliente, de la podredumbre, de lo marginal. En la imaginación de Jaar, nace el gesto político de la obra para leer y exponer esta oculta necesidad de visibilidad en el ideario social. El tema de la imaginación no es un dato menor en la concepción del artista. Baste ubicarse en el lugar de Jaar, para pensar que el proceso imaginativo dio origen a esta obra. Parafraseando a Jacques Derrida (1989), la operación de la imaginación creadora vuelve su mirada a la invisibilidad en la libertad poética. Se trata aquí de una salida fuera del mundo, hacia un lugar que no es ni un no lugar, ni otro mundo, ni una utopía, ni un desvío. Así, la comunidad quedaba intervenida y obligada a ver. He aquí también el acto estético de la obra.

Lo poético de Jaar es lo que aspira a hacer que esa visibilización tiemble en el borde mismo de su posibilidad [...] Es lo que más allá de dar información puesta en palabras, crea experiencias visuales que sugieren y hasta fuerzan a "desenmascararse", a exigir los hábitos mentales del pensamiento moderno. (Valdés 2006, 61)

"Un flash rojo iluminará la cúpula del Mercado Bonsecours cada vez que un individuo en la necesidad se apoye en este disparador" (Jaar 2006, 87). ${ }^{2}$ Este fragmento del texto-instalación que cito cifra una segunda cuestión: el cuerpo marginado se hace luz y el monumento arquitectónico es cuerpo de un calor lumínico que resplandece todos los cuerpos de la marginalidad. Este hacer cuerpo en la luz, esta especie de texto por descifrar, nombra un resto que en su gesto logra restar el sinsentido de esta experiencia social (figura 2).

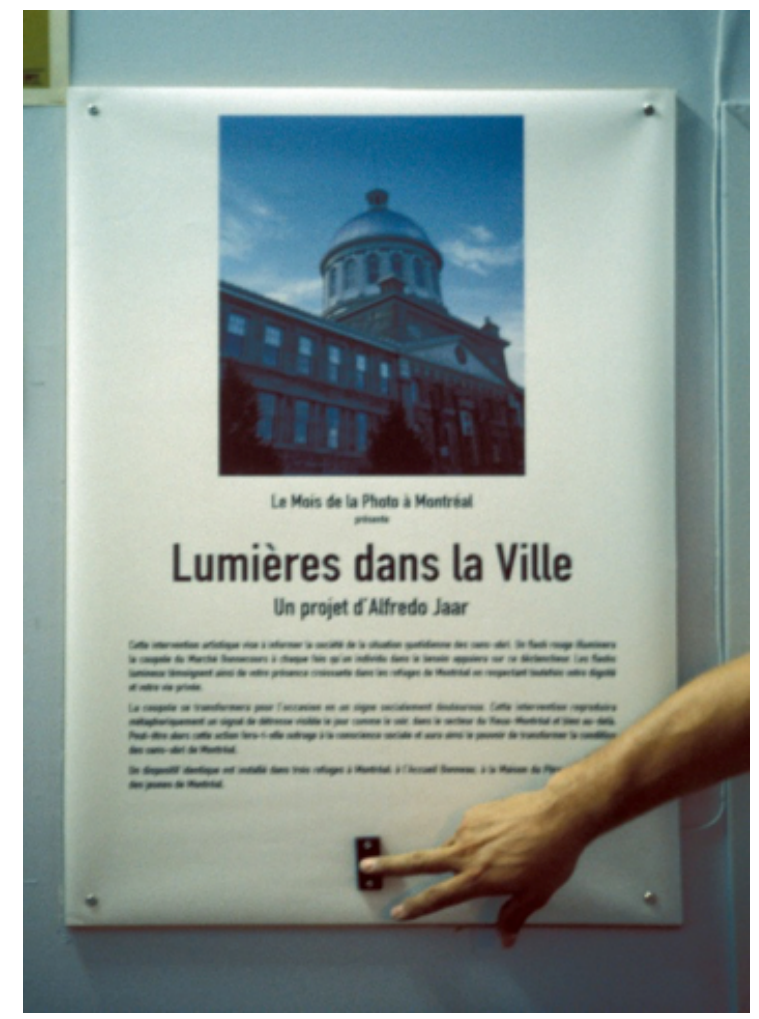

figura 2

Texto y dispositivo ubicado en las hospederías. Fuente: Alfredojaar.net (2013). 
El otro aparece de su clandestinidad obligada como este OTRO en la alteridad del sentido, se hace aparecer en aquello invisible del acontecimiento y, por qué no decir, de la obra realizada en la palabra cuerpo. Justamente, estamos ante el juego del lenguaje imposibilitado de nombrar lo que hay ahí en los márgenes del lenguaje. Homi Babha (2007) nombra, en su crítica histórica reciente, lo indecible del cuerpo marginalidad como la propia supeditación de la cultura ante el imperio del signo. El absolutismo del lenguaje como sistema de significación - la posibilidad misma de hablar - se transforma en el mal gobierno del discurso: el derecho de solo algunos de hablar en forma diacrónica y diferenciada, dejando a los otros solo la posibilidad de hablar marginalmente.

Los estados de margen, borde y frontera nos hacen preguntar en torno a prácticas artísticas que impulsan el sentido mismo del límite y del conocimiento que presentan. Para Sarat Maharaj (2007), existirían maneras diversas de comprender la realidad y de conocer al otro. Una suerte de equipamiento contraepistémico, señala el autor, para aceptar lo distante y lo distinto.

Por esto, la mirada euclidiana, retiniana, cartesiana o significada que se quisiera realizar de esta obra nos imposibilita a estar en el otro lado, en el otro del otro lado, en el afuera o en alguna otra parte en la cual el sentido se aparece ocultando cualquier significado convenido. Precisamente, es en su distancia como relato lo que dona al sentido de la obra, el resto y los restos que no vemos o que no sentimos o que no pensamos bajo los conocimientos tradicionales de la propia visibilidad. Me parece que el sentido de esta obra radica, particularmente, en no darle una significación más que añada lo dicho y los dichos críticos, sino de entrar en ese sentido que ella misma es. Ese algo distinto, esas diferencias de algo distante, que más que aquello que pueda identificarse en la distinción y en la diferencia se aparece desde su opacidad, desde su exterioridad y desde su espaciamiento del sentido en los márgenes de su propia materialidad. ¿Es posible pasar por alto el mundo de los cuerpos o de la obra como cuerpo sin retirarse de lo visible?

Ligths in the City toca lo visible de la invisibilidad de este acontecimiento, ya que en su expropiación el pensamiento queda suspendido sobre el afuera del sentido mismo que nos toca desde la cúpula. En esta operación, se provoca una materialidad productiva, puesto que la obra como acontecimiento inscribe el cuerpo que se nombra en la corporización de los pobres del presente. Así es, señala Zúñiga (2006),

como si la mención del nombre alumbrara una presencia, o trajera a la luz al ausente, a la som-

bra murmurante de ese nombre. Nombre que no es nombrado sino en su propia operación resignificante e in-significante del artificio de "hacer luz: abrir una grieta, precipitar una crisis, dar a pensar. [...] Hacer luz para "comunidades carentes de imágenes" (las cursivas son mías). (118)

Todas las luces, todos los cuerpos, son repartidos en los márgenes de la visualidad. Todos los cuerpos tocan y se tocan. Fuego quemante, que brota de la luz, como si el monumento arquitectónico recordara cada vez sus incendios melancólicos y la reiteración, una y otra vez, de la tragedia del sujeto ausente hecha cuerpo luz. Señala Jaar (2006) que esta muestra del fuego, la cual significó una tragedia para la cúpula, ahora es una muestra de otra tragedia: la falta de vivienda para los sin hogar. Y esta vez, tragedia (fuego) está amenazando no a la cúpula, sino a la sociedad en sí misma. 
Por cierto, cada señal de luz, emitida por los "sin hogar", se transforma en cuerpo doblegado, en un recuerdo doloroso para la comunidad, pero, al fin y al cabo, el destello de la exposición de los cuerpos. La luz, tema tan inquietante para Aristóteles (1978), se hace aquí presente con toda su significación. Cito en su extensión algunas consideraciones fundamentales del filósofo:

La luz, a su vez, es el acto de esto, de lo transparente en cuanto que transparente. Por el contrario, en los cuerpos transparentes en potencia se da la oscuridad. La luz es pues, como el color de lo transparente cuando lo transparente está en entelequia bajo la acción del fuego o de un agente similar al cuerpo situado en la región superior del firmamento. [...] al menos, que lo que se ve a la luz es el color, y de ahí que éste no se vea si no hay luz: la esencia del color, en efecto, consiste en ser el agente que pone en movimiento a lo transparente en acto y la entelequia de lo transparente es, a su vez, la luz. (193)

Por tanto, solo vemos cuando el rayo de luz viaja hacia nuestros ojos y produce una serie de sensaciones y alteraciones químicas en nuestros órganos visuales. Si la luz, como señalaría Aristóteles (1978), es esta especie de color transparente, los cuerpos presentados y arrojados en la obra aludida, destinados a la inmensidad sensible del espectador, provocan, sin lugar a dudas, una opacidad, una suerte de sombra desconocida y descolorida que no vendría a ser sino los cuerpos rememorados por Jaar que el mundo moderno sigue olvidando. ¿Cuáles son esas sombras invisibles que iluminan mi propia sombra? Por cierto, se habla de que los cuerpos poseen sombra, aunque sabemos también que la sombra es un fenómeno creado por la luz. Al observar nuestra sombra, vemos un cuerpo proyectado, algo así como otro cuerpo del propio cuerpo, una verdadera puesta en movimiento que moviliza un cuerpo que no está aquí, sino allá y que, sin embargo, está siempre vinculado con el cuerpo propio tocándose en el borde de su separación. ¿Serán necesarias estas sombras para que se presente la separación y el distanciamiento de los cuerpos?

Se puede suponer que el cuerpo se ve más allá de sus límites, se reconoce en su sombra tal como si espejeara la realidad que lo conforma para habitar el mundo a nuestro lado o a nuestras espaldas. Para Nancy (2003b), "la intimidad del cuerpo expone la aseidad pura como la separación y la partida que ella es. La aseidad —el a-sí-mismo-, por el sí mismo del sujetosolo existe como la separación y la partida de este a —que es el lugar, la instancia propia de su presencia, de su autenticidad, de su sentido" (29). Con lo anterior, Rancière (2008) deja en evidencia lo expuesto cuando señala:

Alfredo Jaar no suprime las imágenes. Nos recuerda que la imagen no es un simple pedazo visible, una puesta en escena visible, un anudamiento de lo visible y de lo que dice, y también de la palabra y de lo que hace ver [...] Vemos demasiados cuerpos sin nombre, demasiados cuerpos que no nos devuelven la mirada que les enviamos, de los que nos hablan sin que se les dé la posibilidad de hablarnos. (47)

Finalmente, la obra en cuestión mantiene una constante de exposición en el color (rojo) que se proyecta desde su altura. El tinte de la proyección no sería cualquier propósito. Deleuze (2003) habla del color como una estructura material espacializante, el acto de la figura, la figura como el hecho, la escena de la figura y el lugar, territorio que encarna el sentido y límite de la obra. La obra se ha realizado en el toque de la sensación. Por este motivo, el tacto toca lo invisible, logra presentar en la superficie el devenir de las intensidades de los cuerpos, en 
una constante infinita que toca la sensación más que la visión. Además, caracteriza el cuerpo como un espacio de movimiento retroactivo al ser este el acontecimiento del espacio-movimiento-tiempo: ¿cuerpos en la obra de Jaar que se movilizan en el tiempo de exposición de la cúpula? Sigamos con Deleuze:

El cuerpo espera algo en sí mismo, hace un esfuerzo sobre sí mismo para convertirse en Figura. Ahora donde pasa algo es el cuerpo: él es fuente de movimiento [...] El cuerpo se esfuerza con precisión, o con precisión espera escaparse. No es el yo quien intenta escapar de mi cuer-

po, es el propio cuerpo quien intenta escaparse por. (25)

Esta salida o exposición de los cuerpos en Jaar se inicia en algún lugar que no es ni un aquí ni un allí con determinación significante. ¿Se podría sostener que la luz puesta en movimiento por Jaar extralimita la posibilidad de significación? Parece ser, entonces, que la relación de los significantes con lo significado en Ligths in the City se ubica en un espacio en el que ninguna figura intermediaria va a asegurar su encuentro: es dentro del conocimiento, el enlace establecido entre la idea de una cosa y la idea de otra (Foucault 2005).

\section{LA PRESENCIA DE LO IMPRESENTABLE: UNA PROPUESTA ESTÉTICA}

Cuerpo hay ahi donde una terrible, imperiosa, inaguantable necesidad se impone, se presenta -ella-. Cuerpo es necesidad: no todo cuerpo es necesario, pero todo lo necesario es cuerpo. Cuerpo hay ahí donde un deseo, que se oculta para que se lo descubra, tiembla ser descubierto, tiembla no ser descubierto [...] Cuerpo es pensamiento necesario.

Patricio Marchant

"Cuerpo hay ahí donde un deseo, que se oculta para que se lo descubra, tiembla ser descubierto, tiembla no ser descubierto" (Marchant 1991, 15). Este breve retorno a la referencia del escritor precisa la necesidad de reflexionar en torno a la producción artística de Alfredo Jaar y su relación con el escenario relacional en que el hombre moderno se hace presencia en la sociedad.

Las palabras de Marchant se vinculan con la obra de Jaar, precisamente en lo que nombra la palabra cuerpo, nombre en cuanto deseo y necesidad de aparecer en su sentido cuerpo, no como una escritura sobre o del, sino escribir el cuerpo (Nancy 2003a) para que su mismidad sea reconocida en la oscuridad. "El cuerpo, sin duda, eso que se escribe, aunque no es en absoluto donde se escribe, ni tampoco el cuerpo es lo que se escribe — sino siempre lo que la escritura excribe" (Nancy 2003c, 67). "Excritura" en cuanto aquello que expone al límite la propia escritura del sentido. Parafraseando a Nancy (2003c), solo hay "excripción" por escritura, pero lo escrito sigue siendo ese otro borde distinto de la inscripción, "mientras significa sobre un borde no deja obstinadamente de indicar algo así como su otro-propio borde" (68). 
Pensar la obra de Jaar no es otra cosa que especular sobre el cuerpo en su trayectoria de luz, de destello, de una brillantez, de una presencia en el aparecer de las luces de los cuerpos proyectados hacia el sentido. Una suerte de iluminar la brillantez orgánica, las fracturas plásticas, los fraseos imaginarios, lo no visible, de escribir la luminosidad precisamente en torno a la ausencia del otro, de lo otro, ausencia pura, como señalaría Derrida (1989), y en consecuencia, no la ausencia del cuerpo como objeto de la materialidad, sino la ausencia de todo cuerpo, su ausencia representacional en la presencia del gesto artístico.

Esta presencia no visible del cuerpo o de los cuerpos soportados en susurros en la obra Ligths in the City (Montreal, 1999) se transforma en el sentido estético de la creación, precisamente al presentar lo "impresentable" de la condición humana extrema. El carácter de lo impresentable manifiesta una zona transgredida y en transgresión de su propio límite estético, ya que, al actuar como oposición a la presentación, se ubica en la sociedad de manera provocante y sugerente.

La operación creativa que Jaar presenta es una especie de pulsión de intervención política, "pulsión de visibilidad" (Valdés 2006) que excede el límite convenido en las estructuras clásicas de producción artística. ¿He aquí el gesto político? ¿Cuerpo de la invisibilidad como política de un gesto? En uno de los textos introductorios de Jaar SCL 2006, Adriana Valdés (2006) sostiene:

No se trata solo de visualizar, de disponer artísticamente los materiales de una obra, aunque también se trate de eso. Se trata de visibilizar, de hacer visible algo que no entra en los esquemas de pensamiento del espectador, algo que los descentre y los perturbe, algo que aparezca como ajeno... pero al mismo tiempo en cierto sentido seduzca, logre introducir una cuña de inquietud en los sistemas de certidumbres. (50)

Consciente también de que existe una comunidad de artistas que explícita e implícitamente trabajan como programa de producción temáticas como las expuestas por Jaar, no es menos cierto que, desde las relaciones señaladas en las instalaciones del artista (imagen-cuerpo-luz), se tiende a intervenir no solo un espacio privado (galería, museo, sala de exposiciones, etc.), sino también una trayectoria que expone en lo público, tanto en la voluminosidad monumental como en la pequeña imagen fotográfica, el sentido del cuerpo en el mundo. Entrar en Ligths in the City es pensar la creación de Jaar como un reflejo especular negativo, o si se quiere, el "negativo" del reflejo del espejo, que tensiona la mirada y el cuerpo del observador, del cuerpo político del vidente.

Retornemos nuevamente a la obra:

Esta intervención artística tiene por objeto informar a la sociedad de la situación diaria de las personas sin hogar. Un flash rojo iluminará la cúpula del Mercado Bonsecours cada vez que un individuo en la necesidad se apoye sobre este disparador. El flash luminoso da prueba así de su presencia creciente en los refugios de Montreal respetando no obstante su dignidad y su vida privada. ${ }^{3}$

Esta cita de texto, que es parte de la instalación vinculada a las hospederías, permite entender el aparecer de la vida indigente que en momentos del cotidiano publicita y manifiesta el ser ignorado de la modernidad, el dolor del olvido. Su estar-en-el-mundo es obra, arte y parte realizada por medio del sentido de la invisibilidad de los cuerpos y de todos los sin parte que tocan el sentido no significante del observador. En Nancy (2003b), esta condición se 
manifiesta en que "ver un cuerpo no es precisamente captarlo en una visión: la vista misma ahí se relaja, ahí se espacia, no abarca la totalidad de los aspectos. El 'aspecto' mismo es un fragmento del trazado (a)real, la vista es fragmentaria, fractal, con eclipses. Por lo demás, es un cuerpo el que ve un cuerpo" (37).

He allí el gesto político de Jaar. He ahí la estética como acto político en disenso. La audacia de esta impronta está en asumir este interrogante: ¿un artista sin parte en la mercancía del arte? Pregunta compleja, en la medida en que los detractores de Jaar sostienen que la producción del artista no sería tal sin un plan presupuestario y una comprometedora participación del capital en la creación e instalación de sus obras. Por cierto, es así, sin embargo, sería muy pequeña la discusión si nos acercamos a sus obras desde el privilegio del financiamiento y la cobertura de costos. La toma de conciencia que permiten sus obras se sostiene no en el precio que cuesta levantarlas, sino en el valor social que poseen: ¿precio o valor por la obra?

Diferenciemos el gesto político como un valor. Jacques Rancière (2006), en una sugerente entrevista, delimita esta operación al señalar:

La noción de los "sin parte" es la noción de un sujeto político, y un sujeto político nunca puede ser identificado sin más con un grupo social. Razón por la cual digo que el pueblo político es el sujeto que encarna la parte de los sin parte —con ello no decimos "la parte de los excluidos", ni que la política sea la irrupción de los excluidos, sino que la política es, ante todo, la acción del sujeto que sobreviene con independencia de la distribución de las partes sociales. (73-74)

"Cuerpo es pensamiento necesario", señala Marchant (1991). Me pregunto, ¿para la comunidad social? Parece ser que paulatinamente esta comunidad ha vuelto su mirada a la catástrofe de la indolencia y de la indiferencia de los cuerpos que realizan la propia comunidad como cuerpo. Cuerpo no vidente de cuerpos que manifiestan la no videncia del otro. Una suerte de pérdida y de marginalidad que es propiamente constitutiva del nombre comunidad social y política moderna.

Se podría pensar en un cuerpo que padece o que comparece frente al presente sin presencia. Como una sustitución de la presencia que ausenta al hombre en todas sus manifestaciones. Podríamos también pensar en un modo conveniente de relaciones, que permiten sustituir el cuerpo del otro como el objeto de deseo y de producción material. En cada comunidad política, el presente del objeto cuerpo se traduce en su propio olvido, en la negación que niega su propia existencia y la presencia de otros cuerpos, como una no experiencia visible que molesta al presente cada vez que se aparece, que se le descubre, que se deja en evidencia su existencia en el temblar de su descubrimiento. Temblor y necesidad, que para Marchant (1991) es también lenguaje y escritura de todo aquello que nombra los límites de la ocultación, los límites de su propio sentido revelado a la comunidad política. Una suerte de cuerpo sin parte, de cuerpo que descorporaliza toda comunidad como su propiedad productiva. ¿Un cuerpo sin órganos? (Deleuze 2006).

Es en este contexto que el gesto político del cuerpo en la obra se traduce en su acción independiente de los otros cuerpos sociales, ya que también a ellos les pertenece. Una especie de mandato invisible que manifiesta la posibilidad de relacionar la noción de cuerpo en la obra como vector de una presencia no visible y, por qué no decir, "impresentable" para la comunidad social; el acto provocativo que realiza el sentido de la obra como intervención en la ciudad, teniendo como referencia la invisibilidad del cuerpo sin parte y, por consiguiente, la búsqueda precisamente más allá del sentido: el sentido del sentido mismo del gesto político de la obra que permite entender la acción política en la estética de Jaar. 


\section{CUERPO, SENTIDO Y COMUNIDAD DE CUERPOS EN “LIGHTS IN THE CITY”}

“La cúpula se transformará para la ocasión en un signo socialmente doloroso. [...] Puede ser entonces esta acción una ofensa a la conciencia social" (Jaar 2006). "Esto es lo que ofrece políticamente Jaar a la comunidad. La cita interpela dos cuestiones interesantes de leer. Por una parte, el cuerpo (el del indigente) aparece en la cúpula como signo de los cuerpos que representa (la indigencia) en su exposición lumínica (signo de sí y ser-símismo del signo). ¡Qué gesto más político! Si pensamos que en su enunciado la indigencia se socializa en el dolor que la luz propaga por la ciudad, me pregunto ¿quién descifra este gesto?, ¿la obra de arte por sí misma?, es decir, ¿su condición de ser obra de arte? Y desde ahí, ¿su vinculación con el observador? Me parece que esta creación artística permite el surgimiento de estos interrogantes. Jaar recontextualiza el concepto de arte al provocar una breve pausa a distancia en el observador: algo que descentre y los perturbe (Valdés 2006). ¿Qué cuerpo es ese capaz de intervenir el cuerpo del otro desde su invisibilidad? Dejaré por el momento en suspenso esta pregunta. Por otra, nos pone en evidencia el propósito oculto de la obra: su acción política. Precisamente, la ofensa a la conciencia social se dirige a la comunidad social como totalidad. Es una acción imperativa que dona, a su vez, el sentido de su necesidad. Sería como una recordación ante el llamamiento que la impunidad y el olvido realizan en la indolencia, comunidad ciega ante el cuerpo visible de la pobreza. Lo político está en la luz como signo del desamparo y de la invisibilidad de los sin hogar. Y, por cierto, se encuentra en la comunidad como la comunidad iluminada de los otros.

La doble operación estético-política nos obliga a entrar en el sentido particular de la exposición del cuerpo en el gesto artístico de Jaar, en el entendido de que la obra Ligths in the City evoca una imagen visible de lo invisible que se espacia como cuerpo y en los cuerpos cifrados. Esta evocación reúne a todos los cuerpos de la pobreza y también a la pobreza como cuerpo que se expone en la luz. Al escribir desde esta posición, escribimos, no en torno a las cualidades fisiológicas, significantes, disciplinares del cuerpo de la pobreza y menos en su condición piadosa o compasiva, sino que escribimos el cuerpo (Nancy 2003c), o si se quiere, la posibilidad de volcar el cuerpo - constituido en la obra - hacia afuera. ¿Es posible realizar así una lectura del cuerpo mismo? ¿Relatar el cuerpo desde su límite? Parece ser que esto es lo provocativo de la obra, la existencia de un cuerpo que toca el sentido desde su inmaterialidad y distanciamiento. "Llega el momento en efecto de escribir y de pensar este cuerpo en el alejamiento infinito que lo hace nuestro, que nos lo hace venir de más lejos que todos nuestros pensamientos: el cuerpo expuesto de la población del mundo" (Nancy 2003c, 13). Por este hecho, los cuerpos tienen un lugar en un límite donde tocan esta ausencia que proviene de algún afuera, de algún lugar que separa o hace de un extraño el significado.

La luz que ilumina el monumento, como recurso estético, posibilita esta sensación sentida y por sentir de un espacio que entra en tensión por la espacialidad de los cuerpos, por su exposición hacia el sentido de su propio límite, hacia el mundo que se encuentra fuera de la cúpula y que se aleja de ese lugar. Los cuerpos viajan por la luz desde el adentro de las hospederías que exponen la indigencia como partida. 
Por esto, las obras de Jaar — no solo la escrita aquí - tocan y tocan en el lugar de su extensión. Como sostiene Nancy (2003b), el cuerpo se hace otro al tocarse ahí, al ser tocado ahí en el sentido de la apertura provocada. Por esto, el filósofo señala que "de un cuerpo no hay nada que descifrar — salvo esto, que la cifra de un cuerpo es ese mismo cuerpo, no cifrado, extenso [...] Mientras los cuerpos estén ahí, disfrutan de la claridad del alba —ella misma lábil en su evidencia, diversa, pausada, desplazada por toques" $(38,39)$.

Sigamos con las interrogaciones: ¿qué sentido tiene concentrar la obra de Jaar en el cuerpo de la invisibilidad miserable? Precisamente porque ahí radica su sentido, no como significación ${ }^{5}$ ni presencia de una determinación denotada, que tendería a presentar sus razones sobre sí misma. El sentido es justamente lo opuesto, su apertura en su propia alteridad, el cual se expone en su distanciamiento, en su ausencia o en su lejanía. Se podría decir que la obra de Jaar en su representación se ha donado como tal, ya que la propia significación se ha puesto en su propio límite; en otras palabras, todos los cuerpos contenidos en la luz del monumento y en el lugar en que cada vez es pulsado el botón que lo ilumina, desde su antítesis arquitectónica (las hospederías), nos ha presentado el límite de la obra propiamente tal en cuanto presencia-a-distancia.

En este contexto, el sentido vendría a ser algo así como la posibilidad de las significaciones que no se han realizado manifiestamente y que quizá sus retornos sean, precisamente, aquellos que se exponen en la luminosidad del edificio. Siguiendo a Nancy (2003c), " no se trata de ajustar una mira, sino de dejar que la cosa se presente en verdad [...] Lo que es verdadero no es una conformidad de lo presentable y de su presentación, que guardará siempre lo presentado a distancia de representación, sino el surgimiento de una presencia" (59). Por esto, el sentido de la obra nos expone en un lugar común, y con ella entramos en su apertura, entramos en contacto como una forma que nos interrumpe: la interrupción está al borde y quizá conforma el borde. Entre esta forma y borde queda un espacio donde los seres se tocan, se exponen, se separan y se comunican entre sí.

En este límite, que a su vez soporta todos los cuerpos, la comunidad recibe la obra aludida, la comunidad recibe el sentido cada vez que esta ausencia se convierte en la posibilidad de referirse a ella. Alfredo Jaar, en su reparto de sentido, desplaza los cuerpos por el espacio y sorprende todas las significaciones para que, en su lugar, y entonces, se produzcan nuevas razones significadas. Por tanto, "el paso del pensamiento suspendido sobre este sentido ya nos ha tocado [...] Todos los cuerpos, los unos fuera de los otros, hacen el cuerpo inorgánico del sentido [...] Todos los sentidos son el sentido, el sentido del mundo es el mundo del sentido" (Nancy 2003b, 28, 103, 233).

Finalmente, la cúpula que instala la obra se transformó en un espacio socialmente doloroso; "tendrá así el poder de transformar la condición de las personas sin hogar de Montreal" (Jaar 2006). ${ }^{6}$ Esto remite al lugar donde la obra cobra su acontecimiento: en la comunidad. Quizá uno de los textos más sentidos que han hablado del tema ha sido el de Maurice Blanchot (2003), La comunidad inconfesable. Señala el filósofo: "Mantenerme presente en la proximidad del prójimo que se aleja definitivamente muriendo, hacerme cargo de la muerte del prójimo como única muerte que me concierne, he ahí lo que me pone fuera de mí y lo que es la única separación que pueda abrirme, en su imposibilidad, a lo Abierto de una comunidad" (24). El hombre moderno, los hombres todos, los cuerpos en la comunidad, han venido reclamando una pérdida paulatina y creciente: su imposibilidad de compartir el sentido como su propia participación en el mundo. Sigamos con Nancy (2009): 
Es posible que el hombre no desee, en el fondo, otra cosa que el "mal": no el buen vivir de Aristóteles, que exige un complemento siempre renovado a la "vida", una expansión más allá de la necesidad, sino, por el contrario, ese otro complemento y esa otra expansión que puede llevar a cabo la aniquilación tanto de sí mismo como de los otros, y de lo común así reducido a la común carbonización. Sí, eso es posible, y la era actual de la humanidad nos representa una comunidad de osarios, hambrunas, suicidios y embrutecimientos. (53)

La creación del artista puso en común el propio estar de la obra, su propio aparecer en la ciudad, su propia luminosidad y, en consecuencia, su destello propio que nos hizo estar junto con los otros cuerpos de la invisibilidad del dolor. En esta singularidad plural, tocamos la obra porque fuimos tocados por ella: "Tocamos en la medida en que nos tocamos, y en que tocamos el resto en cuanto es. Nos tocamos en cuanto que existimos. Tocarnos es lo que nos hace nosotros, y no hay otro secreto por descubrir o por esconder tras este tocar mismo, tras el 'con' de la co-existencia" (Nancy 2006, 29).

Ligths in the City no habla en particular, o si se quiere, singularmente de los homless de Montreal; por el contrario, se puede suponer en su exclusividad una presencia que dispone el espaciamiento de todas las singularidades sin hogar y todas sus obras puestas en la escena de la brillantez de la luz. Cada una de estas, cada uno de estos hombres, corresponden a una apertura hacia el mundo, una llegada cada vez a una nueva presencia del mundo. La obra se distancia de su lugar de origen, ya que revela un secreto que solo el sentido más allá de ella puede declarar: su posibilidad de ser obra de arte y copresencia del mundo en la representación de todos los hombres, que en ausencia o en opacidad, se transforman en luces para una ciudad.

\section{NOTAS}

1 Rodrigo Zúñiga (2008) analiza esta obra con interesantes supuestos sobre la operatoria de instalación de Alfredo Jaar. "El efecto visual sobre el panorama de la ciudad resultaba altamente sugerente: acompasaba sobre ella un juego de luces que marcaba la presencia/ausencia de esos cuerpos, como si esas 'señales de vida' tuvieran por objeto conmemorar, en el silencio de la noche, su condición de ánimas en pena, cuya única inscripción efémera estuviera dada por el indicio de esas luces y cuya presencia sólo pudiera cifrarse bajo el signo del peligro" (106).

${ }^{2}$ Transcribo el texto en francés como aparece en la hospedería: " Un flash rouge illuminera la coupole du Marché Bonsecour á chaque fois qu'un individu dans le besoin appuiera sur ce déclencheur ».

${ }^{3}$ Este fragmento corresponde a una parte del texto que se encuentra en las hospederías de Montreal, para las personas sin hogar y que vincula la obra (instalación) con el cuerpo no visible del indigente. Transcribo esta parte, tal como están presentados en los hogares: "Cette intervention artistique vise à informer la société de la situation quotidienne des sans-abri. Un flash rouge illuminera la coupole du Marché Bonsecour á chaque fois qu'un individu dans le besoin appuiera sur ce déclencheur. Les flash lumineux témoignent ainsi de votre présence croissante dans les refuges de Montréal en respectant toutefois votre dignité et votre vie privée».

${ }^{4}$ Transcribo el texto en francés: "La coupole se transformera pour l'occasion en un signe socialment douloureux. [...] Peut-étre alors cette action fera-t-elle outrage á la conscience sociale ».

${ }^{5}$ Es interesante como Nancy (2003a) se refiere al proceso de significación, ya que "se vacía precisamente porque cierra su proceso subjetivo: no tiene por sentido más que a sí misma, en su inercia, es decir, a la vez su propio deseo, su propia proyección, su propia distancia de representación, además de su propia representación de la distancia" (48).

${ }^{6}$ Transcribo el texto en francés como aparece en la hospedería: « et aura ainsi le pouvoir de transformer la condition des sans-abri de Montréal ». 


\section{REFERENCIAS}

Aristóteles. 1978. Acerca del alma. Traducción de Tomás Calvo. Madrid: Gredos.

Derrida, Jacques. 1989. La escritura y la diferencia. Barcelona: Antrophos.

Babha, Homi. 2007. "Luciérnagas atrapadas en melaza: temas de traducción cultural". Traducido por Adriana Valdés. Santiago de Chile: Universidad de Chile/Doctorado en Filosofía.

Blanchot, Maurice. 2003. La comunidad inconfesable. Madrid: Arena Libros.

Deleuze, Gilles. 2003. Lógica de la sensación. Madrid: Arena Libros.

Deleuze, Gilles y Félix Guattari. 2006. Mil mesetas: capitalismo y esquizofrenia. Valencia: Pre-Textos.

Foucault, Michel. 2005. Las palabras y las cosas. Buenos Aires: Siglo XXI.

Jaar, Alfredo. 2006. “Conversaciones en Chile 2005". En Jaar SCL 2006, 64-87. Santiago de Chile: Actar Editorial.

Marchant, Patricio. 1991. "Discurso contra los ingleses". Revista de Crítica Cultural 2: 13-19.

Maharaj, Sarat. 2007. "Xenoepistemias: instrumental hechizo (provisorio) para sondear (tantear) el arte visual como producción de conocimiento y los regímenes retinianos". Traducido por Adriana Valdés. Santiago de Chile: Universidad de Chile/Doctorado en Filosofía.

Nancy, Jean-Luc. 2003a. El olvido de la filosofía. Traducido por Pablo Perera Velamazán. Madrid: Arena Libros.

Nancy, Jean-Luc. 2003b. Corpus. Traducido por Patricio Bulnes. Madrid: Arena Libros.

Nancy, Jean-Luc. 2003c. El sentido del mundo. Buenos Aires: La Marca.

Nancy, Jean-Luc. 2006. Ser singular plural. Traducido por Antonio Tudela Sancho. Madrid: Arena Libros.

Nancy, Jean-Luc. 2009. La verdad de la democracia. Traducido por Horacio Pons. Buenos Aires: Amorrortu.

Rancière, Jacques. 2006. "Universalizar las capacidades de cualquiera". Archipiélago: Cuadernos de Crítica de la Cultura 73-74: 70-79.

- 2008. "El teatro de las imágenes". En Alfredo Jaar: la política de las imágenes, editado por Adriana Valdés, 69-89. Santiago de Chile: Metales Pesados.

Valdés, Adriana. 2006. "Apuntes para una poética de Alfredo Jaar". En Jaar SCL 2006, 48-63. Santiago de Chile: Actar Editorial.

Zúñiga, Rodrigo. 2006. “El sitio y la fórmula". En Jaar SCL 2006, 112-123. Santiago de Chile: Actar Editorial.

Zúñiga, Rodrigo. 2008. La demarcación de los cuerpos: tres textos sobre arte y biopolítica. Santiago de Chile: Metales Pesados.

\section{Cómo citar este artículo:}

Ferrada Sullivan, Jorge. 2017. "Para una estética de la presencia: cuerpo y sentido en "Lights in the City", de Alfredo Jaar". Cuadernos de Música, Artes Visuales y Artes Escénicas 13 (1): 193-205. https://doi.org/10.11144/javeriana.mavae13-1.puep 